\title{
A probabilistic concept of load assessment of self-ignition engines
}

\author{
Jerzy Girtler, Prof. \\ Gdańsk University of Technology
}

\begin{abstract}
A proposal of probabilistic interpretation of loading process of self-ignition combustion engines, was presented. Probabilistic description of loading the engines was proposed with taking into account known parameters (indices) of their operation. It was demonstrated that instantaneous load of such engines can be considered a random variable. Attention was paid to the fact that the load can be taken as a multi-dimensional random variable. Engine load changes during its operation were considered as the loading process and presented in the form of a multi-dimensional stochastic process whose states are loads considered to be random variables. It was demonstrated that the loading process can be taken as the stochastic one of asymptotically independent incements, stationary and ergodic. Justification of the above mentioned features of the loading process is contained in the presented hypotheses. It was also demonstrated that in testing the load process of self-ignition engines stochastic relation between thermal and mechanical loading should be taken into account.
\end{abstract}

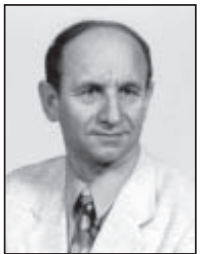

Keywords: hypothesis, load, self-ignition engine, stochastic process

\section{INTRODUCTION}

Loads belong to the crucial causes of wear both surface (linear) and volumetric one, that results in failures of selfignition engines. Especially unfavourable influence on wear of the engines is due to excessive thermal loads in the elements which form their working spaces (combustion chambers). Though mechanical loads of the engines have not so important influence on their wear but if they are excessive (especially those exerted on main and crankshaft bearings) they can also lead to serious failures called breakdowns $[3,7,8,15]$.

It is possible to predict such failures in the case of application of suitable diagnostic systems so designed as to generate full diagnoses, i.e. these capable of predicting their technical state. To elaborate such prediction it is necessary to determine a.o. loads which can appear during operation of engines. In present, loads of combustion engines have been generally analyzed deterministically $[7,9,16,17,18]$. Such analyses based on a probabilistic approach have been performed as a rule in a simplified way. However loads of the combustion engines should be modeled in time and space as random variables attributed to random events in which loads of an appropriate value are measured. The fact that a given load measurement is a random event, means that to which an appropriate probability should be attributed. Moreover the loads should be analyzed in successive instants of operation of combustion engines. The so considered loads form the process of data. Hence it is necessary to elaborate a concept of analyzing and assessing such loads in the probabilistic aspect with taking into account the fact that the load changes successively occurring one by one in the above mentioned instants form a stochastic process. However the instants are not random variables but parameters of the process.
In order to elaborate such concept, probabilistic features of the loading process of combustion engines should be first determined beginning from analysis of states of the process, i.e. the engine loads considered to be random variables.

\section{ENGINE LOADING CONSIDERED AS A RANDOM VARIABLE}

In Introduction it was demonstrated that engine load values can not be precisely predicted. Therefore the following hypothesis $\mathrm{H}_{1}$ can be formulated: „Engine load is a random variable therefore during successively performed measurements its values can be predicted only with a certain probability".

Qualitative interpretation of combustion engine load in an arbitrary instant $t$ can be presented in the following form:

$$
\mathrm{Q}_{\mathrm{D}}(\mathrm{t})=\mathrm{Q}_{\mathrm{C}}(\mathrm{t})+\mathrm{Q}_{\mathrm{M}}(\mathrm{t})
$$

where:

$$
\mathrm{Q}_{\mathrm{C}}(\mathrm{t})=\Delta \mathrm{U}(\mathrm{t})+\mathrm{Q}_{\mathrm{O}}(\mathrm{t})
$$

and

$Q_{D}(t)$ - thermal energy (EC) delivered to engine in the instant $\mathrm{t}$

$Q_{C}(t)$ - thermal energy transferred by engine elements during its operation (thermal loading) in the instant $t$

$Q_{M}(t)$ - mechanical energy associated with presence of gravity and formation of gas forces, friction and inertia forces (mechanical loading) in the instant $\mathrm{t}$

$\Delta \mathrm{U}(\mathrm{t})$ - internal material energy increments, in the instant $\mathrm{t}$, of elements through which a part of the thermal energy $\mathrm{Q}_{\mathrm{C}}(\mathrm{t})$, denoted $\mathrm{Q}_{\mathrm{O}}(\mathrm{t})$, penetrates

$Q_{0}(t)$ - energy emitted to environment in the instant $t$, by walls of engine elements, e.g. those forming working spaces (combustion chambers) and other. 
The above mentioned engine loads can be considered random variables. They result first from transformation of chemical energy contained in fuel into thermal energy, and next - the latter into mechanical one (Fig.1). In the interpretation of the transformations it was taken into account that the heat is a form of transformation of chemical energy into thermal one, and the work - that of thermal energy into mechanical one.

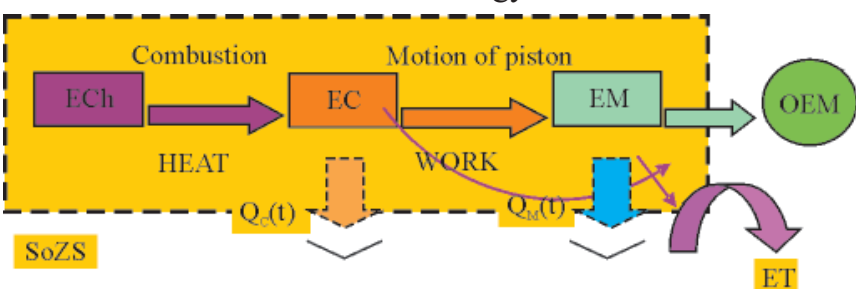

Fig. 1. Example schematic diagram of energy transformation in self-ignition engine: ECh-chemical energy; EC-thermal energy; EM-mechanical energy; ET - thermal and mechanical energy losses; SoZS - self-ignition engine; OEM - mechanical energy consumer (e.g. ship propeller, electric generator, compressor, pump); $Q_{c}(t)$ - thermal load in the instant $t$; $Q_{M}(t)$ - mechanical load in the instant $t$.

In the case when only one parameter (one random quantity) is used for load description then the load (value of the loading process) is one-dimensional random variable. And, if many parameters are used to describe the load (i.e. value of loading process) then it is a multi-dimensional variable. The load is then described by a set of many (generally $n$ in number) random variables. In such case it can be considered to be a n-dimensional random function, i.e. a set of many (n) real functions which attribute unambigously many numerical values to each random event, which load measurement constitutes too $[1,3,4,10,14]$.

In service practice the self-ignition engine load is usually defined by means of the following parameters: $p_{\max }$ - maximum combustion pressure, $\mathrm{t}_{\max }$ - maximum combustion temperature, $\mathrm{p}_{\mathrm{e}}-$ mean effective pressure, $\mathrm{c}_{\text {śr }}-$ mean piston speed, $\Delta \varphi_{\mathrm{psir}}$ - mean pressure rate velocity. The specified parameters can be considered to be values of random variables which can be denoted respectively as follows: $\mathrm{P}_{\max }, \mathrm{T}_{\max }, \mathrm{P}_{\mathrm{e}}, \mathrm{C}_{\mathrm{sr}}$ and $\Delta \Phi$

If the load is determined by means of such random variables as: maximum pressure $\left(\mathrm{P}_{\max }\right)$ and maximum temperature $\left(\mathrm{T}_{\max }\right)$, the two random variables $\left(\mathrm{P}_{\max }, \mathrm{T}_{\max }\right)$ can be considered simultaneously. The variables can be taken stepwise. Then the quantities $\mathrm{p}_{\text {imax }}$ and $\mathrm{t}_{\text {jmax }}$ are arbitrary realizations of the variables. Hence the pair $\left(\mathrm{p}_{\text {imax }}, \mathrm{t}_{\text {jmax }}\right)$ is realization of the two-dimensional random variable $\left(\mathrm{P}_{\max }, \mathrm{T}_{\max }\right)$. Simultaneous occurrence of the events: $\mathrm{P}_{\max }=\mathrm{p}_{\text {imax }}$ and $\mathrm{T}_{\max }=\mathrm{t}_{\mathrm{j} \max }$ is determined by the probability $\mathrm{q}\left(\mathrm{p}_{\text {imax }}, \mathrm{t}_{\text {jmax }}\right)$. In this case all the values $\mathrm{p}_{\text {imax }}$ and $\mathrm{t}_{\text {jmax }}$ which can occur, must follow the relation $[1,10]$ :

$$
\sum_{\mathrm{i}=1}^{\mathrm{r}} \sum_{\mathrm{j}=1}^{\mathrm{r}} \mathrm{q}\left(\mathrm{p}_{\text {imax }}, \mathrm{t}_{\mathrm{jmax}}\right)=1
$$

The set of the probabilities $\mathrm{p}\left(\mathrm{p}_{\text {imax }}, \mathrm{t}_{\text {jmax }}\right)$ constitiutes a twodimensional distribution of the random variable $\left(\mathrm{P}_{\max }, \mathrm{T}_{\max }\right)$.

The probability $\mathrm{p}\left(\mathrm{p}_{\text {imax }}\right)$ of the random event $\mathrm{P}_{\max }=\mathrm{p}_{\text {imax }}$, without taking into account value of the random variable $T_{\text {max }}$, is equal to the sum of the probabilities $\mathrm{p}\left(\mathrm{p}_{\text {imax }}, \mathrm{t}_{\text {jmax }}\right)$, which contains all possible values $t_{\text {jmax }}$, therefore:

$$
\mathrm{q}\left(\mathrm{p}_{\text {imax }}\right)=\sum_{\mathrm{j}=1}^{\mathrm{r}} \mathrm{q}\left(\mathrm{p}_{\text {imax }}, \mathrm{t}_{\text {jmax }}\right)
$$

The set of the probabilities $\mathrm{q}\left(\mathrm{p}_{\text {imax }}\right)$ determined according to Eq. (3), is a boundary distribution of the random variable $\mathrm{P}_{\text {max }}$

In practice it is neccesary to determine the conditional probability $\mathrm{q}\left(\mathrm{p}_{\text {imax }} / \mathrm{t}_{\text {jmax }}\right)$ of the random event $\mathrm{P}_{\max }=\mathrm{p}_{\text {imax }}$ under the condition (assumption): $\mathrm{T}_{\max }=\mathrm{t}_{\text {jmax }}$. This implies that an engine is most loaded mechanically and thermally when in its working spaces (cylinders) maximum pressure and temperature values occur. The probability can be determined by using the formula:

$$
\mathrm{q}\left(\mathrm{p}_{\text {imax }} / \mathrm{t}_{\text {jmax }}\right)=\frac{\mathrm{q}\left(\mathrm{p}_{\text {imax }}, \mathrm{t}_{\text {jmax }}\right)}{\mathrm{q}\left(\mathrm{t}_{\text {jmax }}\right)}
$$

The set of the conditional probabilities $\mathrm{q}\left(\mathrm{p}_{\text {imax }} / \mathrm{t}_{\text {jmax }}\right)$ under the same condition (assumption): $\mathrm{T}_{\max }=\mathrm{t}_{\text {jmax }}$, is a conditional distribution of the random variable $\mathrm{P}_{\max }$ under the condition: $\mathrm{T}_{\max }=\mathrm{t}_{\text {jmax }}$. The sum of the conditional probabilities $\mathrm{q}\left(\mathrm{p}_{\text {imax }} / \mathrm{t}_{\text {jmax }}\right)$ containing all the possible values $\mathrm{p}_{\text {imax }}$ equals one, i.e.:

$$
\sum_{i=1}^{r} \mathrm{q}\left(\mathrm{p}_{\text {imax }} / \mathrm{t}_{\mathrm{jmax}}\right)=1
$$

In practice it may so happen that the random variables $\mathrm{P}_{\text {max }}$ and $\mathrm{T}_{\max }$ are independent, e.g. as a result of an incorrectly performed regulation of engine. Then the following relations are valid:

$$
\begin{gathered}
\mathrm{q}\left(\mathrm{p}_{\text {imax }} / \mathrm{t}_{\text {jmax }}\right)=\mathrm{q}\left(\mathrm{p}_{\text {imax }}\right) \\
\mathrm{q}\left(\mathrm{t}_{\text {jmax }} / \mathrm{p}_{\text {imax }}\right)=\mathrm{q}\left(\mathrm{t}_{\text {jmax }}\right)
\end{gathered}
$$

By taking into account Eq. (6) and (7) in Eq. (4) the following is obtained:

$$
\mathrm{q}\left(\mathrm{p}_{\text {imax }} / \mathrm{t}_{\text {jmax }}\right)=\mathrm{q}\left(\mathrm{p}_{\text {imax }}\right) \mathrm{q}\left(\mathrm{t}_{\text {jmax }}\right)
$$

The random variables $\mathrm{P}_{\max }, \mathrm{T}_{\max }$ which satisfy the condition (8), are stochastically independent. In the case if the condition is not satisfied the random variables $\mathrm{P}_{\max }, \mathrm{T}_{\max }$ are stochastically dependent (correlated) random variables. As results from Eq. (8), in investigations should be taken into account the fact that in the case of the independent random variables $\mathrm{P}_{\max }, \mathrm{T}_{\max }$ their conditional distributions do not differ from their boundary distributions.

The load described by three parameters, for instance the maximum pressure $\mathrm{P}_{\max }$, maximum temperature $\mathrm{T}_{\text {max }}$ and mean effective pressure $\mathrm{p}_{\mathrm{e}}$ can be considered in the same way. Then the three stepwise random variables $\left(\mathrm{P}_{\max }, \mathrm{T}_{\max }, \mathrm{P}_{\mathrm{e}}\right)$ should be considered. The three quantities: $\mathrm{p}_{\text {imax }}, \mathrm{t}_{\mathrm{jmax}}$ and $\mathrm{p}_{\mathrm{ekmax}}$ constitute realizations of the random variables. Hence the three $\left(\mathrm{p}_{\text {imax }}, \mathrm{t}_{\text {imax }}\right.$, $\mathrm{p}_{\mathrm{e}}$ ) is realization of the three-dimensional random variable. The probability of simultaneous occurrence of the events: $\mathrm{P}_{\max }=\mathrm{p}_{\mathrm{imax}}, \mathrm{T}_{\max }=\mathrm{t}_{\mathrm{j} \max }$ and $\mathrm{P}_{\mathrm{e}}=\mathrm{p}_{\mathrm{ek}}$, constitutes the probability $\mathrm{p}\left(\mathrm{p}_{\text {imax }}, \mathrm{t}_{\text {jmax }}, \mathrm{p}_{\text {ek }}\right)$.

In the case of the taking into account of all the values: $p_{\text {imax }}$, $\mathrm{t}_{\mathrm{jmax}}$ and $\mathrm{p}_{\mathrm{ek}}$, which can occur, the following is valid:

$$
\sum_{\mathrm{i}=1}^{\mathrm{r}} \sum_{\mathrm{j}=1}^{\mathrm{r}} \sum_{\mathrm{k}=1}^{\mathrm{r}} \mathrm{q}\left(\mathrm{p}_{\text {imax }}, \mathrm{t}_{\mathrm{jmax}}, \mathrm{p}_{\mathrm{ek}}\right)=1
$$

The set of the probabilities $q\left(p_{\text {imax }}, t_{j \max }, p_{\text {ek }}\right)$ is a three-dimensional distribution of the random variable $\left(\mathrm{P}_{\max }, \mathrm{T}_{\max }, \mathrm{P}_{\mathrm{e}}\right)$.

The probabilities $\mathrm{q}\left(\mathrm{p}_{\text {imax }}\right)$ of the random variable: $\mathrm{P}_{\max }=\mathrm{p}_{\text {imax }}$, without taking into account value of the random variable $T_{\text {max }}$ as well as the random variable $P_{e}$, is equal to the sum of the probabilities $q\left(p_{\text {imax }}, t_{j \max }, p_{\text {ek }}\right)$ which covers all the possible values of $\mathrm{t}_{\mathrm{jmax}}$ and $\mathrm{p}_{\mathrm{ek}}$, hence:

$$
\mathrm{q}\left(\mathrm{p}_{\text {imax }}\right)=\sum_{\mathrm{j}=1}^{\mathrm{r}} \sum_{\mathrm{k}=1}^{\mathrm{r}} \mathrm{q}\left(\mathrm{p}_{\text {imax }}, \mathrm{t}_{\mathrm{jmax}}, \mathrm{p}_{\mathrm{ek}}\right)
$$

The set of the probabilities $\mathrm{q}\left(\mathrm{p}_{\text {imax }}\right)$ which follow Eq. (10), is a boundary distribution of the random variable $\mathrm{P}_{\max }$. 
The presented proposal of description of the load of combustion engines is important as the load impacts wear of their elements. For this reason, the wear in a given instant of operation time of the engines is also a random variable, and when analyzed in successive instants of the operation, their values should be considered as those following a random process.

\section{ENGINE LOADING CONSIDERED AS A STOCHASTIC PROCESS}

As commonly known, in trying to maintain engine's continuous power rate or its rated power, in successive instants engine's mechanical load values are rather close to each other, depending on operational conditions. And, engine's thermal load values can, in presence of the mechanical loads, vary and even exceed to a great extent their limit values. It results from the dependence of thermal load not only on mechanical one but also on a state of engine's cooling system, lubricating oil quality, pressure in lubricating system of bearings, oil quantity delivered to lubricate cylinder liners, etc $[4,7,8,12]$.

The loading (mechanical and thermal) of engines can be considered in a dynamic (short) time interval measured in [ms] (i.e. that in which one or at most a few thermodynamic cycles of engine occur), or in that quasi-static (long) which is equivalent to a correct engine operation time interval usually measured in $[\mathrm{h}]$.

By comparing the loads which occur during successive thermodynamic cycles, i.e. during the short time interval $\left(\mathrm{t}_{\mathrm{d}}\right)$, one can state that they are different because different causes $[7,8,16,17,18]$. Along with increasing values of the engine operation time $t_{d}$ the differences are also increasing. Hence at a given value of the dynamical time interval and in investigating the loads during particular cycles in the instants $t_{d 1}, t_{d 2}, \ldots$, one can obtain different engine load values. The event of obtaining a given value of the load is random one. It means that to each instant of the time $t_{d}$ a random variable equivalent to the engine load in that instant, can be attributed. In the same way to each instant of the quasi-static time $\left(\mathrm{t}_{\mathrm{q}}\right)$ a random variable equivalent to the engine load in that instant, can be attributed.

The engine load taken as a random variable in a given instant $t$, constitutes value of the loading process. In turn, the process constitutes a run of consecutive load changes causually inter-connected in function of time, and possible to be described by different random parameters (quantities) whose values can be predicted only with a certain probability. Hence the loading process is stochastic, i.e. a function whose values for a given time instant of engine operation, $t$, are randomly variable. Therefore the following hypothesis $\mathrm{H}_{2}$ can be formulated: "The engine loading process is stochastic because values of the engine loading in a given time instant (which is not a random variable) are randomly variable".

As results from the theory of stochastic processes the set of such instants is that of parameters of the process [6, 14].

The engine loading process is stochastic one of continuous realizations. However by its discretization the stochastic process of constant realizations within particular time intervals of engine operation, can be achieved. The so modified loading process (process of load changes) can be described in the form of a semi- Markovian model which has a strictly determined set of loading states, [4, 6, 14].

The engine loading can be characterized by means of various quantities (parameters, indices). Generally, it can be expressed in the following form (11):

where:

$$
\mathrm{Q}(\mathrm{t})=\mathrm{f}\left[\mathrm{Q}_{\mathrm{M}}(\mathrm{t}), \mathrm{Q}_{\mathrm{C}}(\mathrm{t})\right]
$$

Q - engine's loading
$\mathrm{Q}_{\mathrm{M}}$ - engine's mechanical loading

$\mathrm{Q}_{\mathrm{C}}$ - engine's thermal loading

$\mathrm{t}$ - engine's operation time interval.

In empirical loading investigations at least two stochastic processes: $\left\{\mathrm{Q}_{\mathrm{M}}(\mathrm{t}): \mathrm{t} \geq 0\right\}$ and $\left\{\mathrm{Q}_{\mathrm{C}}(\mathrm{t}): \mathrm{t} \geq 0\right\}$ can be considered. They are components of the vectorial process $\{\mathrm{Q}(\mathrm{t}: \mathrm{t} \geq 0\}$, $[4,9,16,17,18]$.

In the case of the loads $\mathrm{Q}_{\mathrm{M}}$ and $\mathrm{Q}_{\mathrm{C}}$ it can be possible to write that they are vectors of the following components in a given instant $t$ :

$$
\begin{aligned}
& \mathrm{Q}_{\mathrm{M}}:\left[\mathrm{p}_{\max }, \mathrm{p}_{\mathrm{z}}, \mathrm{p}_{\mathrm{e}}, \mathrm{c}_{\mathrm{sr}}, \varphi, \varphi_{\mathrm{p}}, \mathrm{n}, \mathrm{P}_{\mathrm{g}}, \mathrm{P}_{\mathrm{b}}, \ldots\right] \\
& \mathrm{Q}_{\mathrm{C}}:\left[\dot{\mathrm{q}}, \nabla \mathrm{T}, \rho, \mathrm{p}_{\mathrm{e}}, \mathrm{c}_{\mathrm{sr}}, \mathrm{T}_{\text {max }}, \mathrm{T}_{\mathrm{z}}, \mathrm{T}_{\mathrm{sw}}, \dot{\mathrm{Q}}, \ldots\right]
\end{aligned}
$$

where:

$\mathrm{p}_{\max }-$ maximum combustion pressure; $\mathrm{p}_{\mathrm{z}}-$ combustion pressure; $p_{e}-$ mean effective pressure $\left(p_{e}=\eta_{m} p_{i} ; \eta_{m}-\right.$ mechanical efficiency; $p_{i}$ - mean indicated pressure)

$\mathrm{c}_{\mathrm{s} r} \quad$ - mean piston speed; $\varphi$ - degree of isochoric pressure increment; $\varphi_{\mathrm{p}}$ - instantaneous pressure increase rate; $\mathrm{n}$ - engine crankshaft rotational speed; $\mathrm{P}_{\mathrm{g}}$ - gas pressure force; $\mathrm{P}_{\mathrm{b}}$ - inertia force; $\dot{\mathrm{q}}$ - thermal flux (energy) density; $\nabla \mathrm{T}$ - temperature gradient; $\rho$-degree of initial isobaric decompression; $\mathrm{T}_{\max }$ - maximum combustion temperature; $\mathrm{T}_{\mathrm{z}}$ - combustion pressure; $\mathrm{T}_{\mathrm{sw}}$ - exhaust gas temperature; $\mathrm{Q}$ - heat flux; $\mathrm{T}_{\mathrm{ol}}$ - oil temperature; $\mathrm{T}_{\mathrm{w}}-$ cooling water temperature.

As results from Eqs. (11) $\div(13)$, the engine loading depends on many quantities (parameters, indices), hence it can be considered a stochastic process which contains superposition (composition) of particular individual processes (in the simplest case - that of $\mathrm{Q}_{\mathrm{M}}$ and $\mathrm{Q}_{\mathrm{C}}$ ). Such interpretation of the loading is suitable for general considerations but it may be rather not useful for practical purposes.

The loading can be also considered to be a vectorial process whose components are random variables which characterize load values in particular instants of engine operation time, described in the form of Eqs. (12) and (13).

Generally, the loading can be understood as a process whose states can be taken into account in the form of random variables. The process, as observed from Eqs. (12) and (13), is mult-dimesional because it can be determined only when load parameters which form a complete set of parameters, are measured and probabilities of obtaining their values determined.

The complete set of load parameters (indices) can be interpreted as that which contains all the parameters necessary to determine engine's loading.

In every instant $t_{d 1}(1=1,2, \ldots, n)$, of the dynamic time interval $t_{d}, n$ following random variables: $Q_{t}, Q_{t}, \ldots, Q_{t}$, can be considered. The variables have been further denoted: $Q_{1}$, $\mathrm{Q}_{2}, \ldots, \mathrm{Q}_{\mathrm{n}}$. They can stand for $\mathrm{n}$ different quantities (parameters, indices) of investigated loading (e.g. $\mathrm{Q}_{1}=\mathrm{p}_{\max }, \mathrm{Q}_{2}=\mathrm{T}_{\max }, \mathrm{Q}_{3}$ $=\mathrm{p}_{\mathrm{e}}, \mathrm{Q}_{4}=\dot{\mathrm{q}}$, etc) .

If particular load features are simultaneously considered (the load can be characterized by an excessive combustion pressure, excessive combustion temperature, excessive heat flux, etc) the set of $\mathrm{n}$ random variables, being a $\mathrm{n}$ - dimensional random variable, is obtained. Hence at a distinguished instant $t$ the loading $\mathrm{Q}(\mathrm{t})$ can be considered to be a n- dimensional random variable $\mathrm{Q}_{\mathrm{t}}$ (further marked $\mathrm{Q}$ ). Therefore the so considered loading can be determined by a set of $\mathrm{n}$ real unambiguous functions which attribute numerical values to every random event (i.e. occurence of a given load value). 
Generally, in order to simplify further considerations, they can be limited by assuming that the random variable $Q$ will be a two-dimensional random function $\left(\mathrm{Q}_{\mathrm{M}}, \mathrm{Q}_{\mathrm{C}}\right)$. For the reason that measurements are periodically executed it can be assumed that the random variables $\mathrm{Q}_{\mathrm{M}}$ and $\mathrm{Q}_{C}$ are stepwise (non-continuous) random ones. Realizations of the variables are respectively the quantities: $\mathrm{q}_{\mathrm{Mi}}$ and $\mathrm{q}_{\mathrm{Ci}}$. Hence the pair $\left(\mathrm{q}_{\mathrm{M}_{\mathrm{i}}}, \mathrm{q}_{\mathrm{C}_{\mathrm{i}}}\right)$ is realization of the random variable $\left(\mathrm{Q}_{\mathrm{M}}, \mathrm{Q}_{\mathrm{C}}\right)$. The variable takes the values $\left(\mathrm{q}_{\mathrm{Mi}}, \mathrm{q}_{\mathrm{C}_{\mathrm{i}}}\right)$ with a determined probability $\mathrm{p}\left(\mathrm{q}_{\mathrm{Mi}}, \mathrm{q}_{\mathrm{C}_{\mathrm{i}}}\right)$ which is that of simultaneous occurrence of the events:

$$
\mathrm{Q}_{\mathrm{M}}=\mathrm{q}_{\mathrm{Mi}} \text { and } \mathrm{Q}_{\mathrm{C}}=\mathrm{q}_{\mathrm{Ci}}
$$

The set of the above mentioned probabilities $\mathrm{p}\left(\mathrm{q}_{\mathrm{M}_{\mathrm{i}}}, \mathrm{q}_{\mathrm{C}_{\mathrm{i}}}\right)$ constitutes the two-dimensional distribution of the random variable $\left(Q_{M}, Q_{C}\right)$. In a similar way as in the preceding considerations which have made it possible to formulate Eqs. (2) and (3), the mentioned distribution $\mathrm{p}\left(\mathrm{q}_{\mathrm{M}_{\mathrm{i}}}, \mathrm{q}_{\mathrm{C}_{\mathrm{i}}}\right)$ satisfies the following condition:

$$
\sum_{\mathrm{i}=1}^{\mathrm{r}} \sum_{\mathrm{j}=1}^{\mathrm{r}} \mathrm{p}\left(\mathrm{q}_{\mathrm{M}_{\mathrm{i}}}, \mathrm{q}_{\mathrm{C}_{\mathrm{j}}}\right)=1
$$

The boundary distribution of the random variable $Q_{M}$ is as follows:

$$
\mathrm{p}\left(\mathrm{q}_{\mathrm{M}_{\mathrm{i}}}\right)=\sum_{\mathrm{j}=1}^{\mathrm{r}} \mathrm{p}\left(\mathrm{q}_{\mathrm{M}_{\mathrm{i}}}, \mathrm{q}_{\mathrm{C}_{\mathrm{j}}}\right)
$$

and, the distribution of the random variable $Q_{C}$ has the following form:

$$
\mathrm{p}\left(\mathrm{q}_{\mathrm{C}_{\mathrm{j}}}\right)=\sum_{\mathrm{j}=1}^{\mathrm{r}} \mathrm{p}\left(\mathrm{q}_{\mathrm{M}_{\mathrm{i}}}, \mathrm{q}_{\mathrm{C}_{\mathrm{j}}}\right)
$$

From the investigations have been performed so far it results that some quantities which characterize the loading, e.g. $p_{e}, c_{s r}$ $[3,16,17,18]$ characterize both mechanical and thermal one. Therefore it is obvious that there are relations between the mechanical and thermal load. For the reason that they constitute random processes a stochastic relationship between them should be expected. Hence to explain the relationship the following hypothesis $\mathrm{H}_{3}$ can be formulated: „Between the mechanical load $Q_{M}(t)$ and the thermal load $Q_{C}(t)$ a stochastic relationship occurs because determined variants of one of the variables are accompanied by different variants of the other."

Therefore it yields that the relationship between the loads: $\left(\mathrm{Q}_{\mathrm{M}}(\mathrm{t})\right.$ and $\left.\mathrm{Q}_{\mathrm{C}}(\mathrm{t})\right)$ cannot be described by using the common method of algebraic equations. This seems true as the loading depends on a large number of factors including those nonmeasurable $[2,3,12,14]$ :

During the main energy transformation process in combustion engine (Fig. 1) thermal energy is transformed into mechanical one, but not inversely. Hence the thermal load $\left(Q_{C}\right)$ can be conventionally assumed an independent variable, and the mechanical load $\left(Q_{M}\right)$ - a dependent variable. Analogously, it can be assumed that $\mathrm{Q}_{\mathrm{C}_{1}}, \mathrm{Q}_{\mathrm{C}_{2}}, \ldots, \mathrm{Q}_{\mathrm{C}_{\mathrm{n}}}$, are independent variables, but $\mathrm{Q}_{\mathrm{M}_{1}}, \mathrm{Q}_{\mathrm{M}_{2}}, \ldots, \mathrm{Q}_{\mathrm{M}_{\mathrm{n}}}$ - dependent ones.

A degree in which the load $\mathrm{Q}_{\mathrm{M}}$ is determined - either by the load $\mathrm{Q}_{\mathrm{C}}$, or $\mathrm{Q}_{\mathrm{C}}(\mathrm{j}=1,2, \ldots, \mathrm{n})$ considered to be independent variables, may be very different. In practice it may happen that one independent variable $\left(Q_{C}\right)$ almost fully determines the dependent variable $\left(Q_{M}\right)$. However it may also happen that a few independent variables $\left(Q_{C}\right)$ only to a small extent influence the dependent variable $\left(Q_{M}\right)$. ${ }^{j}$ From the above said it results that there is a necessity of taking into account an intensity (force) of the stochastic relationship between $\mathrm{Q}_{C}$ and $\mathrm{Q}_{\mathrm{M}}$.

The intesity (force) of the stochastic relationship between $\mathrm{Q}_{\mathrm{M}}(\mathrm{t})$ and $\mathrm{Q}_{\mathrm{C}}(\mathrm{t})$ can be determined, during empirical investigations, by using the relationship [10]:

$$
\mathrm{T}_{\mathrm{MC}}^{2}=\mathrm{T}_{\mathrm{CM}}^{2}=\frac{\chi^{2}}{\mathrm{~N} \sqrt{(\mathrm{k}-1)(1-1)}}
$$

where:

$\mathrm{k}$ - number of variants of the variable $\mathrm{Q}_{\mathrm{M}}$

1 - number of variants of the variable $Q_{C}$

$\mathrm{N}$ - boundary number of the variable $\mathrm{Q}_{\mathrm{M}}$ or $\mathrm{Q}_{\mathrm{C}}$

$\chi^{2}-$ value calculated from chi- square formula

$\mathrm{T}_{(\cdot)}^{2}-$ Czuprow's convergence coefficent.

It can be proved [10] that $\mathrm{T}_{\mathrm{MC}}$ takes values from the interval $[0,1]$. The coefficient equals zero $\left(\mathrm{T}_{\mathrm{MC}}=0\right)$ if no relationship between values of the process $\left(Q_{M}\right.$ and $\left.Q_{C}\right)$ occurs, and if it is equal to $1\left(\mathrm{~T}_{\mathrm{MC}}=1\right)$ a functional relationship takes place. Hence from the hypothesis $\mathrm{H}_{3}$ on the relationship between the loads $\mathrm{Q}_{\mathrm{M}}$ and $\mathrm{Q}_{\mathrm{C}}$ the following consequence $\mathrm{K}$ can be derived: $\mathrm{T}_{\mathrm{MC}}=\mathrm{T}_{\mathrm{CM}} \neq 0=\mathrm{T}_{\mathrm{MC}} \neq 1$.

Assuming that the syntactic implication $\mathrm{H} \Rightarrow \mathrm{K}$ is true, to verify the hypothesis the following methods can be applied $[11,13]$ :

the reductive reasoning which proceeds according to the scheme:

$$
(\mathrm{K}, \mathrm{H} \Rightarrow \mathrm{K}) \vdash \mathrm{H}
$$

the "modus tollens" rule which proceeds in line with the scheme:

$$
(\sim \mathrm{K}, \mathrm{H} \Rightarrow \mathrm{K}) \vdash \sim \mathrm{H}
$$

where: the symbols -- sign that the hypothesis $H$ is true.

In this case, application of the reductive reasoning can be justified by the following:

is Mechanical load increasing as a rule always results in thermal load increasing as an increase of the torque $M_{0}$ requires an increase of the fuel charge $\Delta \mathrm{G}_{\mathrm{p}}$, i.e. that of the chemical energy contained in the charge. The charge increase makes it possible to develop a greater thermal energy inside the engine combustion chamber (working space). A part of the energy is transformed into the mechanical energy (EM) in the form of work (Fig.1) and the remaining part, the lost energy (ET), is transferred by the chamber walls to cooling medium and - together with exhaust gas - to the environment.

is Despite the mechanical load does not undergo large changes, the thermal load can be significantly increased due to worsening the cooling conditions, e.g. due to sedimentation of mineral deposits on cooling space surface, air penetration to the space, etc.

Despite the reductive reasoning does not guarantee that the conclusion that $\mathrm{q}_{\mathrm{M}}$ has increased is true, the relation: $\left(\mathrm{q}_{\mathrm{M}} \Rightarrow \mathrm{q}_{\mathrm{C}}\right)$ $\cap \mathrm{q}_{\mathrm{C}}$ is true. However it does not mean that, if the implication: $\left(\mathrm{q}_{\mathrm{M}} \Rightarrow \mathrm{q}_{\mathrm{C}}\right)$ on the interpretation that if the mechanical load $\mathrm{q}_{\mathrm{M}}$ increases the thermal load $\mathrm{q}_{\mathrm{C}}$ " also increases, it can not be assumed true that if $\mathrm{q}_{\mathrm{C}}$ increases then also $\mathrm{q}_{\mathrm{M}}$ increases, i.e.:

$$
\left[\left(\mathrm{q}_{\mathrm{M}} \Rightarrow \mathrm{q}_{\mathrm{C}}\right) \cap \mathrm{q}_{\mathrm{C}}\right] \Rightarrow \mathrm{q}_{\mathrm{M}}
$$

And, application of the ,modus tollens" rule results from that the scheme of reasoning on the hypothesis $\mathrm{H}_{3}$ is reliable and leads to its falsification. However it is so only in the case if empirical investigations are truly capable of undeniable contradicting the hypothesis $\mathrm{H}_{3}$, i.e. that the mechanical load will increase.

It is possible to state generally whether the random variables $\mathrm{Q}_{\mathrm{M}}$ and $\mathrm{Q}_{\mathrm{C}}$ are mutually dependent, by investigating the probabilities determined with the use of the general equations: $(14) \div(16)$ or those detailed: $(6) \div(8)$. 
In the case when - as in the detailed considerations - the conditional distributions of the variables do not differ from their boundary distributions, the following is valid:

$$
\mathrm{p}\left(\mathrm{q}_{\mathrm{M}_{\mathrm{i}}}, \mathrm{q}_{\mathrm{C}_{\mathrm{j}}}\right)=\mathrm{p}\left(\mathrm{q}_{\mathrm{M}_{\mathrm{i}}}\right) \mathrm{p}\left(\mathrm{q}_{\mathrm{C}_{\mathrm{j}}}\right)
$$

It means that the random variables $Q_{M}$ and $Q_{C}$ are independent. And, if Eq. (21) is not satisfied they are stochastically dependent. In this case verification of the hypothesis $\mathrm{H}$ can follow the schemes similar to those presented in the form of Eqs. (18) and (19).

Investigation of stochastic relationship between the random variables $Q_{M}$ and $Q_{C}$ is difficult because distributions of the investigated loads (including conditional distributions) can differ in many features (variability, concentration, asymmetry etc). Hence it is much easier to examine statistical relationship between the mentioned random variables $Q_{M}$ and $Q_{C}$.

It should be observed that if no stochastic relationship between the random variables $Q_{M}$ and $Q_{C}$ takes place then any statistical relationship does not take place between them too. However reverse implication is not true. It directly results from that the same conditional mean values are related to the same conditional distributions, whereas to the same conditional mean values the same distributions are not to be related $[1,10]$.

The statistical relationship is distinguished by that to particular mechanical load values to attribute a mean value of thermal load, or reversely, is possible.

Investigation of statistical relationship between any random variables is realized by means of statistical ordered series or appropriate regression equations which make it possible to determine whether a correlation takes place between the mentioned loads and - if it does -whether it is positive or negative. In practice particular realizations of self-ignition engine loads are observed. In the case if realizations of load for a given time instant $t$ differ only a little, i.e. if its particular values for a given time instant $t$ constitute (for increasing n, i.e. number of load measurements) the series of random variables $\mathrm{Q}_{\mathrm{n}}(\mathrm{n}=1,2, \ldots)$, then the series is stochastically convergent to zero under the following condition, $[1,10]$ :

$$
\lim _{\mathrm{n} \rightarrow \infty} \mathrm{P}\left\{\left|\mathrm{Q}_{\mathrm{n}}\right|>\varepsilon\right\}=0
$$

for an arbitrary number $\varepsilon>0$.

The above is equivalent to the statistical convergence of the series of random variables $\left\{Q_{n}\right\}$ toward the constant value $\mathrm{q} \neq 0$, hence - to the statistical convergence of the random variables $\left\{\mathrm{Q}_{\mathrm{n}}-\mathrm{q}\right\}$ toward zero, that can be expressed as follows $[1,10]$ :

or

$$
\lim _{n \rightarrow \infty} P\left\{\left|Q_{n}-q\right|>\varepsilon\right\}=0
$$

$$
\lim _{\mathrm{n} \rightarrow \infty} \mathrm{Q}_{\mathrm{n}}=\mathrm{q}
$$

The relation (24) makes it possible to consider loads as a deterministic process, i.e. that statistical having prediction error equal to zero. In such process the past fully determines the future.The simplification consisting in the assumption that " the loading constitutes a deterministic process" is commonly applied in investigating the engine loads. However it makes load assessment to be fully adequate to reality both as regards to its features, especially to be capable of rational forming its run, i.e. its rational steering, and - if possible - its optimal control, difficult.

Comparing the loads occurring in successive cycles (number of cycles $n \geq 4$ ), hence within the time interval $t_{d}$ (short), one can state that they are different. The differences are increasing along with increasing $\mathrm{n}$, i.e. when considering the load within the time interval $\mathrm{t}_{\mathrm{q}}$ (long). For this reason different load values are obtained at a determined value of the time interval $t_{d}$ and during investigation of the load in particular cycles at the instants $\mathrm{t}_{\mathrm{d} 1}, \mathrm{t}_{\mathrm{d} 2}, \ldots$ The fact of obtaining a given (expected) load value is a random event. This is such event because as a result of determination of the same empirical conditions the expected load value can occur, but it can also not occur. It means that a random variable can be attributed to every instant $t_{d}$. Similarly, to every instant $t_{q}$ a relevant random variable can be attributed.

From the above presented considerations it results that the following hypothesis $\mathrm{H}_{4}$ can be formulated: „The loading is a process of asymptotically independent increments because along with increasing partition between the time intervals within which the load is investigated (load measurements are made) its values are less and less mutually dependent".

Another feature which characterizes load changes consists in that observed load values do not show any monotonic changes both in the dynamic time $\left(t_{d}\right)$, i.e. that necessary to realize one engine cycle and in the quasi-static time $\left(\mathrm{t}_{\mathrm{q}}\right)$ in which the engine delivers power to a consumer, e.g. screw propeller. Hence it can be assumed that peak values of the quantities which characterize the loading, appear at random. Therefore to unambigously (precisely) predict an instant of its occurrence, is not possible. The lack of monotony feature of engine load changeability makes it possible to formulate the hypothesis $\mathrm{H}_{5}$ as follows: „The loading is a stationary process because in a longer time the monotony feature of engine load changes is lacking".

The load stationarity (in a broader sense) means that in each case all multi-dimensional probability density functions depend only on the mutual distance of the instants $\tau_{1}, \tau_{2}, \ldots, \tau_{\mathrm{n}}$, and do not depend on themselves $[2,5,12,14]$. Hence onedimensional probability density function of load values does not depend on the instant which the value corresponds with, and two-dimensional one depends only on difference of the instants in which observed load values have appeared. And, in a narrower sense, the stationary loading (fully stationary) is understood as that whose all statistical moments of higher orders as well as total moments of the loading (considered as a process) does not depend on time. In the case of the stationary process (in a narrower sense) the expected value $\mathrm{m}(\mathrm{t})$, variance $\mathrm{V}(\mathrm{t})$, auto-correlation $\mathrm{A}\left(\tau_{1}, \tau_{2}\right)$ and auto-covariance $\mathrm{K}\left(\tau_{1}, \tau_{2}\right)$ do not change. And, the stationary process in a broader sense is characterized by that $\mathrm{m}(\mathrm{t})=\mathrm{m}=$ const as well as $\mathrm{A}\left(\tau_{1}, \tau_{2}\right)=$ $A^{*}\left(\tau_{2}-\tau_{1}\right)=A^{*}(r)$. In practice, the stationarity of the loading in a broader sense is of importance.

To confirm the presented features of the stochastic process which the engine loading constitutes, it is necessary to perform relevant empirical investigations. From the tests of selfignition engines, have been carried out so far, it results that their loading is changing continuously so that its particular values measured after passing very short time intervals, are strongly correlated to each other. However, if the time partition between measurements increases, correlation between the loads decreases. Hence the loading values measured within time intervals (or instants) very distant from each other, can be assumed independent. The feature is called the asymptotic independence of the load value measured e.g. in the instant $\tau_{\mathrm{i}+1}$ and the value measured in the instant $\tau_{\mathrm{i}, \mathrm{e}}$ i.e. when the partition (time distance) $\Delta \tau=\tau_{i+1}-\tau_{\mathrm{i}}$ is sufficiently long. The so considered asymptotic independence between load values measured or calculated in the instants $\tau_{\mathrm{i}}$ and $\tau_{\mathrm{i}+1}$ illustrates the fact that along with increasing $\Delta \tau$ dependence between them is decreasing. And, from the self-ignition engine work principle results also that within a longer time of its correct operation there is no (and can not be) monotonously increasing or 
decreasing changes. Hence it can be assumed that maximum load values appear at random in determined instants, therefore they can be predicted only with a certain probability. This lack of monotony feature is called the load stationarity.

Therefore it can be assumed that verification of the presented hypothesis can be performed by checking the following consequences which result from it:

$-\mathrm{K}_{1}: \mathrm{m}_{1}(\mathrm{t})=\mathrm{m}_{1}=\mathrm{const}$

$-\mathrm{K}_{2}: \mathrm{A}\left(\mathrm{t}_{1}, \mathrm{t}_{2}\right)=\mathrm{A} *\left(\mathrm{t}_{2}-\mathrm{t}_{1}\right)=\mathrm{A} *(\Delta \mathrm{t})$

To verify the hypothesis in question the reductive reasoning in accordance with Eq. (18) can be used.

Hence the hypothesis $\mathrm{H}_{6}$ of the following content can be formed: „The loading of every engine is an ergodic process because the loading values do not depend on its initial state".

The hypothesis is of practical importance as it implies that the loading can be cosidered to be a stochastic process in which observation probability of the value $\mathrm{q}(\mathrm{t})$ belonging to the strictly determined set $\mathrm{A} \subset \mathrm{R}$, can be estimated by means of the mean time of presence of each of its realizations in the set at a long time of observation (measurements). This hypothesis - together with the preceding one - explains why vibro-acoustic diagnostics of machines in which vibro-acoustic signal is assumed stationary and ergodic, is useful in practice. As results from the just presented hypotheses, this is an obvious assumption as the loading (cause) generates vibro-acoustic signal (consequence).

The statement whether the loading (taken as a stationary process) is ergodic, consists in comparing its statistical characteristics (expected value, auto-correlation, variance etc) achieved as a result of averaging the realization set $\left\{\mathrm{q}_{\mathrm{k}}(\mathrm{t})\right\}$, with the statistical characteristics obtained as a result of averaging a single, sufficiently long realization of the loading.

As results from the hypotheses (from the $3^{\text {rd }}$ to the $5^{\text {th }}$, inclusive), the loading investigated in the instants very distant from each other, can be considered a purely random process, i.e. such stochastic process in which all the random variables $\mathrm{q}_{\mathrm{t}}\left(\mathrm{t} \in \mathrm{R}_{+}\right)$, in the discrete time $\left(\mathrm{t}_{\mathrm{d}}\right)$, are mutually independent.

The presented opinion on engine load features may lead to new possibilities in empirical determining wear- to- load relationships. Probabilistic approach to engine load is presented in some publications, e.g. [2, 4, 12], where it have been assumed that load realization is normal process and its values are random variables following the Moivre - Gauss distribution.

\section{FINAL REMARKS AND CONCLUSIONS}

In the presented analysis and synthesis of events it was demonstrated that the loading of every self-ignition engine considered in a given instant of its time of operation (work), can be taken as a multi-dimensional random variable. The loading analyzed in successive instants of operational time of such engines can be considered to be realizations of the loading process. Hence the loading process of every engine should be investigated under assumption that it is a multi-dimensional stochastic process. The hypotheses have been proposed why it is possible to assume that the loading process of any self-ignition engine can be taken as a stochastic process of asymptotically independent increments, and stationary and ergodic one, as well as that there is stochastic independence between its mechanical and thermal loads. Intensity of the stochastic relationship can be stated by using the Czuprow's test of convergence [10] during investigations.
For verification of the presented hypotheses the method of non-deductive (inductive) reasoning called the reductive reasoning, as well as the deductive reasoning method called the ,modus tollens" rule, have been proposed.

To recognize features of the processes it is necessary to form relevant mathemetical models by using the system modeling and by performing suitable empirical investigations.

From the preliminary considerations it results that the loading processes of combustion engines are the processes whose features can be analyzed by applying the theories of decision (controlled) semi-Markov processes [4, 5].

\section{BIBLIOGRAPHY}

1. Firkowicz S.: Statistical assessment of quality and reliability of electronic lamps (in Polish). Scientific Technical Publishers (WNT), Warszawa 1963

2. Gercbach I.B., Kordonski Ch.B.: Reliability models of technical objects (in Polish). Scientific Technical Publishers (WNT), Warszawa 1968

3. Girtler J.: Control of the operation process of ship combustion engines on the basis of diagnostic decision making model (in Polish). Scientific Bulletins of AMW, no. 100A, Gdynia 1989

4. Girtler J.: Stochastic model of load spectrum of self-ignition engine (in Polish). Problems of Operation of Machines (Zagadnienia Eksploatacji Maszyn). Quarterly of Polish Academy of Sciences (Kwartalnik PAN), no. 1/97, 1994

5. Girtler J.: Physical aspects of application and usefulness of semi-Markov processes for modeling the processes occurring in operational phase of technical objects. Polish Maritime Research, Vol. 11, No 3, September 2004

6. Grabski F.: Theory of semi-Markov operational processes of technical objects (in Polish). Scientific Bulletins of AMW (Zeszyty Naukowe AMW), no. 75A, Gdynia 1982

7. Gurbin I.B., Syrkin P.E.: Ekspluatacionnaja nadežnost' avtomobilnych dvigatelej (in Russian). Moscow, Transport 1984

8. Karpov Ł.N.: Nadežnost' $i$ kaczestwo sudovych dizelej (in Russian). Moscow, Transport 1985

9. Kozłowiecki H.: Bearings of piston combustion engines (in Polish). Warszawa, Telecommunication and Transport Publishers (WKiE) 1982

10.Krzysztofiak M., Urbanek D.: Statistical methods (in Polish). Polish Scientific Publishers (PWN), Warszawa 1979

11.Leszek W.: Empirical investigations (in Polish). ITE, Radom 1997

12.Niewczas A.: Foundations of stochastic model of frictional wear in durability problems of machine elements (in Polish). Scientific Bulletins (Zeszyty Naukowe), Mechanics (Mechanika) no. 19, Radom University of Technology (Politechnika Radomska), 1989

13.Pabis S.: Methodology and methods of empirical sciences (in Polish). Polish Scientific Publishers (PWN), Warszawa 1985

14.Rozanov Ju.A.: Stacionarnye slučajnye processy (in Russian). Fizmatgiz, Moscow 1963

15.Spiridonov Ju.N., Rukavišnikov N.F.: Remont sudovych dizelej (in Russian). Transport, Moscow 1989

16. Wajand J.A.: Self-ignition engines (in Polish). Scientific Technical Publishers (WNT), Warszawa 1980

17.Włodarski J.K.: Piston combustion engines. Tribological Processes (in Polish). Telecommunication and Transport Publishers (WKi亡), Warszawa 1981

18. Voinov A.N.: Sgoranie v bystrochodnych poršnevych dvigateliach (in Russian). Mašinostroenie, Moscow 1977.
CONTACT WITH THE AUTHOR
Jerzy Girtler, Prof., D.Sc.
Faculty of Ocean Engineering and Ship Technology
Gdansk University of Technology Narutowicza 11/12
80-952 Gdansk, POLAND
e-mail :.jgirtl@pg.gda.pl 